\title{
GOVERNANCE ON INTELLIGENCE: ISSUES THAT PLAY A ROLE
}

\author{
Michel RADEMAKER
}

\begin{abstract}
The intelligence landscape evolves with the spread of electronic communications and networks, surveillance technologies, abundance of open source data, and private actors undertaking intelligence activities. The activities of intelligence agencies and other actors needs to be mandated by law, with the necessary restrictions on the use of the data collected and conditions regarding governance and oversight by internal and external bodies, in compliance with human rights norms.
\end{abstract}

Keywords: Intelligence assessment, NSA files, mandate, democratic oversight, human rights.

\section{Introduction}

Intelligence gathering is an activity of all times. Everybody collects information: the grocery shop owner, the company CEO, donor organisations, marketing organisations, media, universities and research organisations, and states. The assessment of the collected intelligence ${ }^{1}$ is the development of forecasts of behaviour or recommended courses of action to the leadership of an organisation, based on a wide range of available information sources, both overt and covert. Assessments are developed in response to requirements declared by the leadership in order to inform decision making. An assessment may be carried out on behalf of a state or a military or commercial organisation, with a range of sources of information available to each.

Nowadays, information gathering is easy. Big datasets develop overnight, are available in the cloud and simple distribution, collection and assessment tools are developed with them, often very cheap or free of charge (Figure 1). ${ }^{2}$ Social media, internet and all kinds of (statistical) databases are piling up. So, being an intelligence officer of your own is within armes length and relatively cheap. 


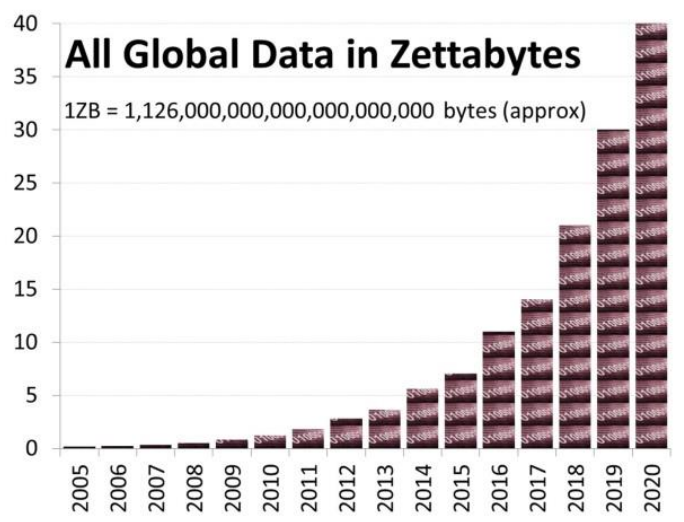

Figure 1: The future development of big data growth.

However, not all types of information are allowed to be gathered just because it is available. And when special data collection means are being used, privacy and security issues start playing a role. Especially in democratic constitutional states intelligence gathering and assessment is seen as an activity that is important to undertake but at the same time to be organised as transparent as possible with maximum oversight and checks and balances for privacy and security. These checks and balances are difficult to organise or to execute, especially when the intelligence gathering is done under secrecy.

Because state intelligence gathering and assessment organisations, the ,intelligence and security services community, " are often by law given special permission to collect and assess data and information that not only is publicly available but also needs special or covert operations, extra requirements are set for governance.

These days the PRISM files of the US National Security Agency (NSA) released by Mr. Snowden reveal some of the means states use to collect and assess information. And because of the massiveness of the collected information, the means to collect it and the subject that information is collected from (citizens, Chancellor of Germany Angela Merkel, industry and others), questions are again raised on the mandates, the necessary oversight and democratic control of intelligence and security services.

\section{Mandates}

Most intelligence services in democratic constitutional states have been mandated to collect and assess information under condition that it is only used for counter terrorism, preventing espionage against the state, preventing industrial espionage, etc. When organised properly, governments develop laws that define the mandates, means, type of use of collected and assessed information but also the way it should be 
classified, archived or disposed. In democratic constitutional states public scrutiny is possible. Sometimes parts of these laws are kept secret as well and here an unbalance might occur. The mandates come with restrictions on the use of the data collected and conditions regarding governance and oversight. Depending on the level of openness, which is often culturally determined, differences in the standards of democratic control show up.

\section{Governance and democratic oversight}

The theories of governance and proper democratic control and oversight are clearly defined. The Council of Europe in its European Convention on Human Rights ${ }^{3}$ has made generally accepted statement dispositions that might be related to intelligence governance in its articles amongst others such as Prohibition of torture (Article 3), Right to liberty and security (Article 5), Right to a fair trial (Article 6), No punishment without law (Article 7), Right to respect for private and family life (Article 8), Freedom of expression (Article 10), Right to an effective remedy (Article 13) and Prohibition of discrimination (Article 14).

At the United Nations, the Human Rights Council in its 2010 report addressed the promotion and protection of human rights and fundamental freedoms while countering terrorism. Special Rapporteur Martin Scheinin compiled good practices on legal and institutional frameworks and measures that ensure respect for human rights by intelligence agencies while countering terrorism, including on their oversight. ${ }^{4}$ And it also defined the purpose of intelligence services, namely to "collect, analyse and disseminate information that assists policymakers and other public entities in taking measures to protect national security. This includes the protection of the population and their human rights." Also in the European Court of Human Rights and in jurisprudence of these bodies it is generally accepted that national security is one of the criteria that legitimizes breaches in fundamental rights. ${ }^{6}$ In general, although not defined very precisely, national security is seen as what is necessary for a democratic society.

Key elements of good practices defined by these bodies are:

- Oversight of the different activities of intelligence services should include internal and external bodies. External and independent bodies are essential;

- All activities should be regulated by publicly available national laws and in compliance with international laws, especially international human rights laws;

- There should be a system which allows intelligence members to report wrongdoings, and to individuals to complain against invasion; 
- All measures to assure the privacy of personal data of individuals should be taken.

In theory, democratic control is formulated as having organised proper parliamentary control, independent external control, executive control and internal control but also the possibility for complaints and legal certainty. The way these types of control are organised differ widely among states. Benchmarking of oversight mechanisms in European countries ${ }^{7}$ shows that not all elements are well in place, that different states have implemented parts but not all key requirements, that the contextual situation of a country often dominates and prescribes what a country wants to implement and what not, etc.

The European Union member states have different political systems, tasks and responsibilities of intelligence and security services, different powers and underlying political cultures. It is for that reason that it is hard to formulate the ideal type of democratic oversight and, in general, the power of good oversight is probably best taken care of via different mixes of oversight regimes because no single regime is in itself beatific.

A gap in the checks and balances of oversight could be related to the fact, that more and more information gathering and assessment is done by private entities that do not fall under the intelligence and security services laws. These private organisations, being commercial or non-governmental, do not fall under the governance and oversight of the laws. And because it is common knowledge that sometimes up to 90 percent of all intelligence information is open source, but smartly combined, others than the intelligence community can do assessments too. The question is whether the activities of these private actors are regulated at all.

The current upheaval regarding the activities of the United States and others is cause for some states to be worried about the legality and necessity of intelligence gathering and assessment. Some sources make claims that the intelligence gathered was not for national security reasons but for economic and political use only. And it is made clear that most countries do it in some way or the other (legal or not).

It is for this reason that in a timeframe, where information is piling up and doubles by the day, democratic constitutional states need to have extra checks and balances for their own intelligence and security services, as well as police, and extend these checks and balances to private enterprises too. They should also seek guarantees from other states that when information is exchanged or asked for, this information is gathered and assessed within the boundaries of the fundamentals of the laws and regulations measured by the highest standards, and certainly within the frameworks of internationally accepted and well regarded institutions such as the United Nations, its 
Human Rights Council and the Council of Europe in its European Convention on Human Rights.

Because the laws and regulations differ so much between states, for reasons explained above, and because the scientific field is very specialized and young, we will probably witness further developments in the near future. Debate on the topic is necessary and will take place for sure. Hopefully, not only just in democratic constitutional states.

\section{Notes:}

1 “Intelligence assessment," Wikipedia, http://en.wikipedia.org/wiki/Intelligence (information_gathering) (5 Nov. 2013).

2 "Big Data," MSIS Wiki, http://www1.unece.org/stat/platform/display/msis/Big+Data (5 Nov. 2013).

3 European Convention on Human Rights, as amended by Priotocols Nos. 11 and 14, supplemented by Protocols Nos. 1, 4, 6, 7, 12 and 13 (Strasbourg: European Court of Human Rights, Council of Europe), www.echr.coe.int/Documents/Convention_ENG.pdf (12 Nov. 2013).

4 Compilation of good practices on legal and institutional frameworks and measures that ensure respect for human rights by intelligence agencies while countering terrorism, including on their oversight, Report of the Special Rapporteur on the promotion and protection of human rights and fundamental freedoms while countering terrorism, Martin Scheinin, A/HRC/14/46 (UN General Assembly, Human Rights Council, 17 May 2010), https://www.fas.org/irp/eprint/unhrc.pdf (12 Nov. 2013).

5 Ibid., p. 5.

6 Erik J. Frinking and J.G.M. Rademaker, "Inlichtingen en Veiligheidsdiensten," in Nationale Veiligheid en inlichtingen, eds. B. A. de Graaf, E. R. Muller, and Joop van Reijn (Alphen aan den Rijn: Kluwer, 2010), 189-204, quote on p. 193.

7 Aidan Wills, Mathias Vermeulen, Hans Born, Martin Scheinin, and Micha Wiebusch, Parliamentary Oversight of Security and Intelligence Agencies in the European Union (Brussels: European Parliament, Directorate General for Internal Policies, 2011), http://www.europarl.europa.eu/document/activities/cont/201109/20110927ATT27674/2011 0927ATT27674EN.pdf (12 Nov. 2013).

MICHEL RADEMAKER MTL is Deputy Director of The Hague Centre for Strategic Studies (HCSS). HCSS was established in 2007 as an independent think tank. The Centre conducts strategic research and analyses on issues of international and national security and defence. Website: www.hcss.nl. 


\section{Bibliography}

Big Data. MSIS Wiki, 2013.

European Convention on Human Rights, as amended by Priotocols Nos. 11 and 14, supplemented by Protocols Nos. 1, 4, 6, 7, 12 and 13. Strasbourg: European Court of Human Rights, Council of Europe, 2013.

Frinking, Erik J., and J.G.M. Rademaker. "Inlichtingen en Veiligheidsdiensten." In Nationale Veiligheid en inlichtingen, 189-204. Alphen aan den Rijn: Kluwer, 2010.

Intelligence assessment. Wikipedia, 2013.

Scheinin, Martin. Report of the Special Rapporteur on the promotion and protection of human rights and fundamental freedoms while countering terrorism. UN General Assembly, Human Rights Council, 2010.

Wills, Aidan, Mathias Vermeulen, Hans Born, Martin Scheinin, and Micha Wiebusch. Parliamentary Oversight of Security and Intelligence Agencies in the European Union . Brussels: European Parliament, Directorate General for Internal Policies, 2011. 